\title{
Mini-scarotomy-assisted Ponseti method in a posteromedial-released recurrent pes equinovarus case
}

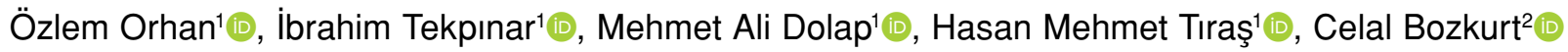 \\ 'Department of Orthopedics and Traumatology, Harran University, Faculty of Medicine, Şanlıurfa, Turkey \\ ${ }^{2}$ Department of Orthopedics and Traumatology, Gaziosmanpaşa Training and Research Hospital, Istanbul, Turkey
}

The gold-standard treatment method in clubfoot patients is the Ponseti method, which has been shown to be successful until advanced ages. Despite this, several surgeries, particularly posteromedial releases (PMRs) are currently performed in resistant, neglected, or recurrent deformities. Recurrence after index surgery traditionally requires further revision surgeries; however, these are associated with a higher risk. ${ }^{[1]}$ Recent studies have suggested that the Ponseti method can be successful in treating recurrent deformities after PMR. ${ }^{[2-4]}$ However, rigid medial scar tissue may prevent deformity correction.

Herein, we report a case in whom initial PMR surgery failed and was treated with a new modified method consisting of classical Ponseti method and mini-scarotomy of the rigid scar tissue.

Received: October 22, 2021

Accepted: December 18, 2021

Published online: December 18, 2021

Correspondence: Özlem Orhan, MD. Harran Üniversitesi Tıp Fakültesi Ortopedi ve Travmatoloji Anabilim Dalı, 63290 Haliliye, Şanlıurfa, Türkiye.

E-mail: droorhan@gmail.com

Doi: 10.52312/jdrscr.2022.12

Citation: Orhan Ö, Tekpınar I, Dolap MA, Tıraş HM, Bozkurt C. Mini-scarotomy-assisted Ponseti method in a posteromedialreleased recurrent pes equinovarus case. $\mathrm{Jt}$ Dis Relat Surg Case Rep 2022;1(1):19-22.

(02022 All right reserved by the Turkish Joint Diseases Foundation

This is an open access article under the terms of the Creative Commons Attribution-NonCommercial License, which permits use, distribution and reproduction in any medium, provided the original work is properly cited and is not used for commercial purposes (http://creativecommons.org/licenses/by-nc/4.0/).

https://www.casereportsjointdrs.org

\section{ABSTRACT}

Although the gold-standard treatment of clubfoot is the Ponseti method, several surgical procedures can be applied in case of resistant, recurrent, or neglected cases. Recurrent deformities after posteromedial release (PMR) may be revised conservatively with Ponseti method. We present a 12-month-old male patient with recurrent pes equinovarus after a failed serial casting followed by PMR. The patient had rigid scar tissue on the medial side of the foot after PMR, which prevented deformity correction. The scar tissue was released with mini-incisions and Ponseti method was applied. The patient had bilateral plantigrade feet at the sixth-month follow-up, and the Pirani score was 0.5. In conclusion, rigid scar tissue may prevent manipulation in revisions with the Ponseti method following PMR. The release of scar tissue with mini-scarotomy can grant a safe revision with the Ponseti method, even after failed surgery.

Keywords: Clubfoot, medial scar, Ponseti method, posteromedial release.

\section{CASE REPORT}

A 12-month-old male patient with bilateral recurrent clubfoot, who was treated in an external center, was admitted to our outpatient clinic. The history of the patient revealed that the deformity recurred after serial casting (method unknown) and percutaneous achillotomy. Due to recurrence, the patient underwent PMR and the forefoot of both feet were adducted, both hindfeet were in equinus, and heels were in varus position. The Pirani score was six in both feet and there was a rigid scar tissue on both incision scars (Figure 1a, b). We decided to apply classical Ponseti method. We noticed that the improvement in the deformity did not progress any further after the fourth casting as scar tissue prevented correction. We, therefore, decided to perform mini-scarotomy to the most stretched points of the scar tissue. We applied local anesthetics and applied scarotomy with a No. 11 

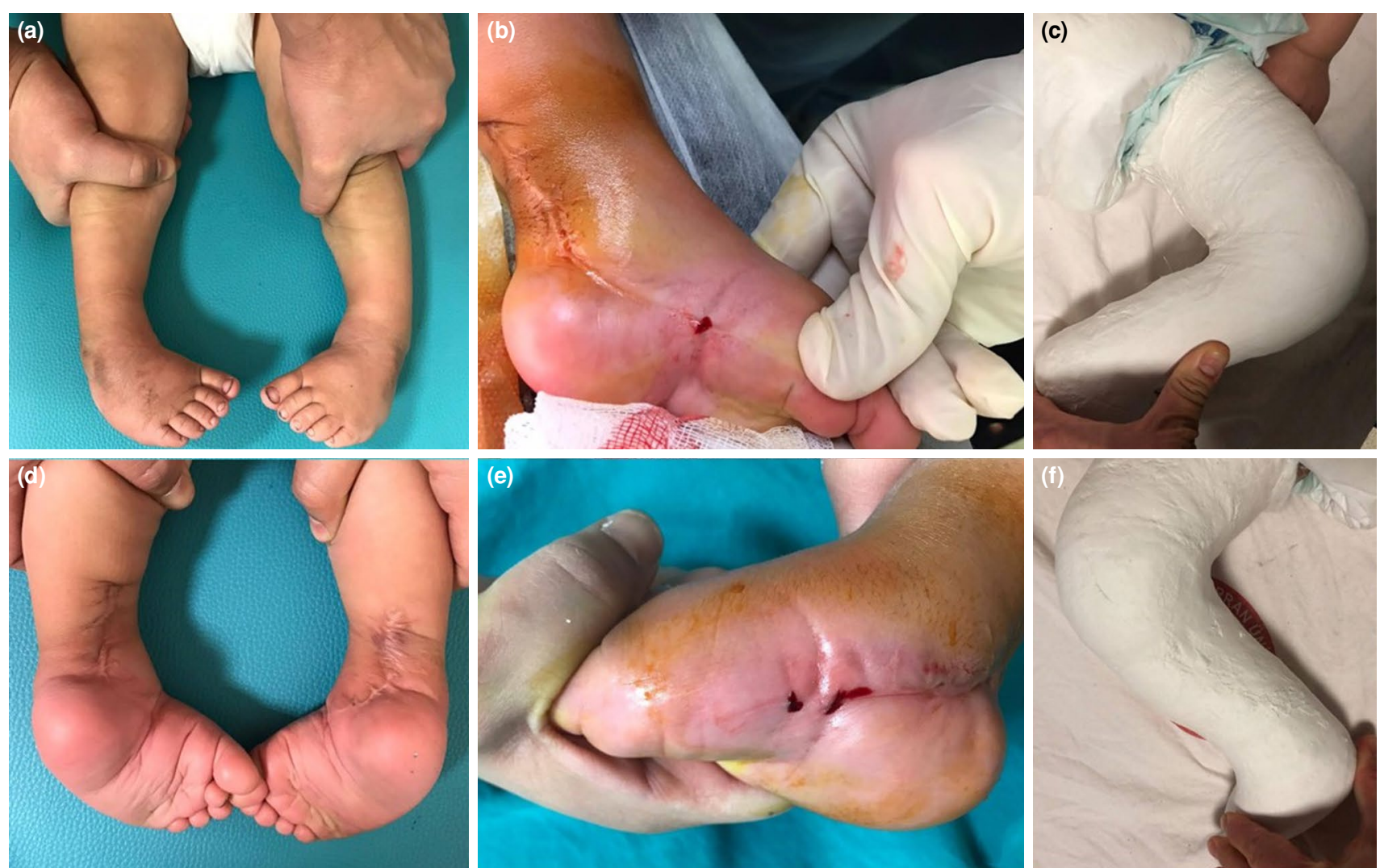

Figure 1. (a, b) First admission examination of the patient with recurrent clubfoot deformity after bilateral PMR to the clinic; (c) Left foot mini-scarotomy application; (d) Right foot mini-scarotomy application; (e) Long leg correction plaster application with Ponseti technique on the left foot; (f) Long leg correction plaster application with Ponseti technique on the right foot.

PMR: Particularly posteromedial releases.

scalpel blade. During the procedure, approximately a 0.5 -cm mini-incision was made at the right angle to the cord structure in the scar tissue. The procedure can be repeated, if there was another scar tissue that prevented manipulation on the examination. We examined the foot during scarotomy and applied second scarotomy for each incision scar. We achieved the relaxation of the rigidity in both feet. Then, we placed sterile dressings on the wound and performed manipulation of the feet. At nine weeks, we repeated the scarotomy. We discontinued manipulation and casting at the end of the $11^{\text {th }}$ cast after we reached
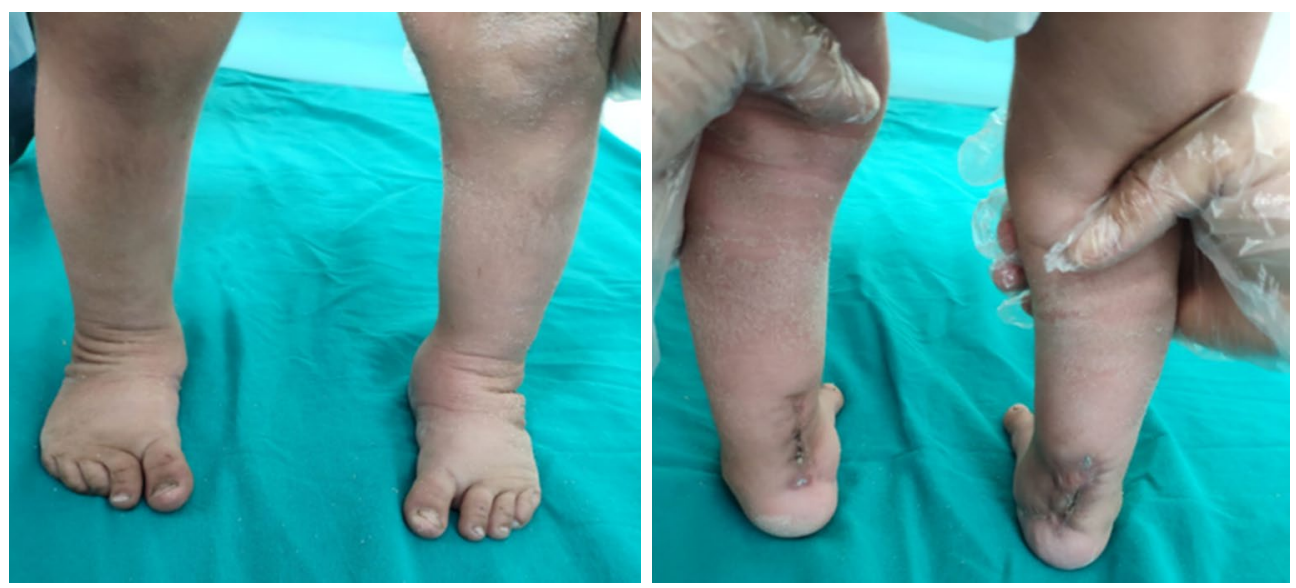

Figure 2. Clinical images at three months of follow-up. 

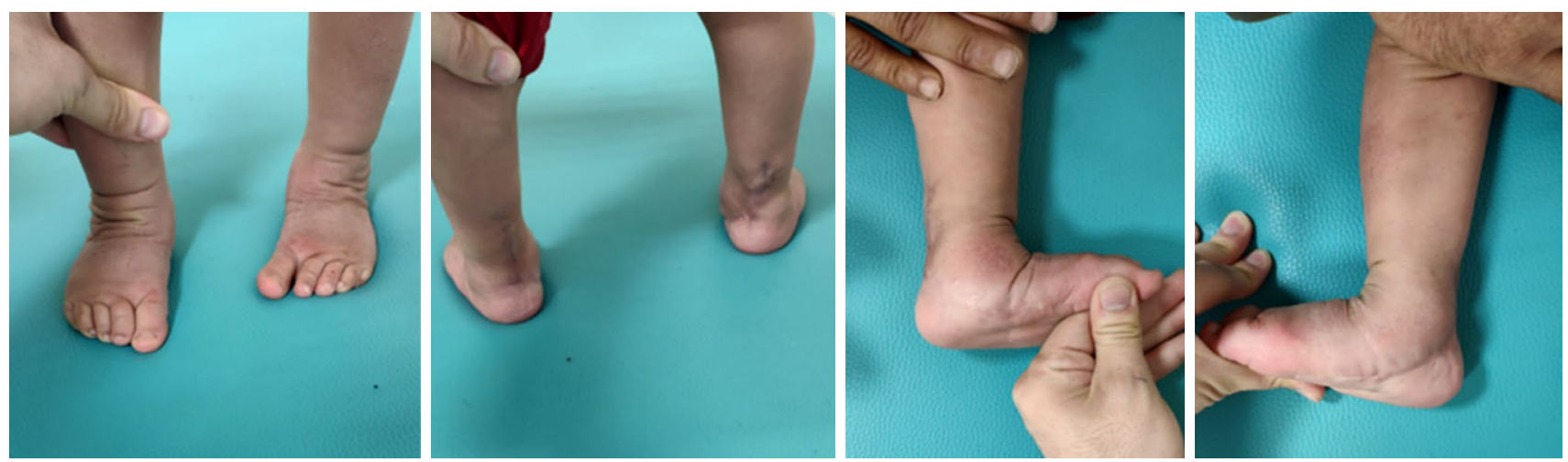

Figure 3. Clinical images at six months of follow-up.

desired abduction and heel valgus. There was still residual equinus deformity. We planned an Achilles tendon lengthening surgery. However, as the Achilles tendon was too thin and weak and there were adhesions around both of the tendons, we decided to release the tendons and posterior capsule. This resulted in a gain of $20^{\circ}$ dorsiflexion in both ankles. Long leg cast was re-applied and was removed three weeks later (Figure 1). Finally, a foot abduction brace was recommended with the feet in $45^{\circ}$ of abduction. We examined the patient in every two weeks, until the end of two months. Afterwards, the patient was followed every month.

At three months of follow-up, there was no bilateral adduction deformity, the heel was neutral, and bilateral dorsiflexion of $5^{\circ}$ was detected (Figure 2). The patient had bilateral plantigrade feet at six months of follow-up, and the Pirani score was 0.5 (Figure 3). A written informed consent was obtained from the parents of the patients for the publication of this case report.

\section{DISCUSSION}

Serial manipulation and casting are applied to restore correction in patients with recurrent clubfoot deformities. Existing scars in patients undergoing previous surgical procedures may not allow adequate manipulation. In this group of patients, mini-scarotomy, which is a rather novel technique, can be applied to scars that prevent correction in the outpatient setting.

In a study by Dobbs et al., ${ }^{[5]}$ there was a weak relationship between the number of surgical procedures and radiological and functional results in patients with clubfoot. Review of the literature reveals that repeated surgical release deviates from the expected functional results in recurrent cases after PMR. ${ }^{[1,3,6,7]}$ Fibrosis on the feet treated with the surgical release is associated with recurrence of the deformity or incomplete recovery, contractures, and stiffness. ${ }^{[4]}$ On the other hand, mini-scarotomy technique, which is less invasive and applied in the outpatient clinic, is not likely to cause complications commonly associated with the surgical release.

Nogueira et al. ${ }^{[4]}$ emphasized that successful results could be obtained with the Ponseti method in cases that recurred after PMR. However, not being able to accurately measure the flexibility of the wounds was a limitation of this study. In our patient, scar tissue prevented manipulation. Therefore, a mini-scarotomy was performed.

We recognize follow-up period in current reports. However, favorable results were obtained in our case. Further long-term, large-scale, prospective studies are needed to confirm these findings.

In conclusion, soft tissue release surgery should not be performed immediately in recurrent cases following PMR. However, in cases of persistent deformity following an open release, as in our patient, combining mini-scarotomy to the areas that prevent the correction with the Ponseti method may be a reasonable option.

\section{Declaration of conflicting interests}

The authors declared no conflicts of interest with respect to the authorship and/or publication of this article.

\section{Funding}

The authors received no financial support for the research and/or authorship of this article.

\section{REFERENCES}

1. Gupta A, Singh S, Patel P, Patel J, Varshney MK. Evaluation of the utility of the Ponseti method of correction of clubfoot deformity in a developing nation. Int Orthop 2008;32:75-9. 
2. Garg S, Dobbs MB. Use of the Ponseti method for recurrent clubfoot following posteromedial release. Indian J Orthop 2008;42:68-72.

3. Al-Hilli AB. Ponseti method in the treatment of postoperative relapsed idiopathic clubfoot after posteromedial release. A short term functional study. Foot (Edinb) 2020;45:101721.

4. Nogueira MP, Ey Batlle AM, Alves CG. Is it possible to treat recurrent clubfoot with the Ponseti technique after posteromedial release?: A preliminary study. Clin Orthop Relat Res 2009;467:1298-305.
5. Dobbs MB, Nunley R, Schoenecker PL. Long-term follow-up of patients with clubfeet treated with extensive soft-tissue release. J Bone Joint Surg Am 2006;88:986-96.

6. Lourenço AF, Morcuende JA. Correction of neglected idiopathic club foot by the Ponseti method. J Bone Joint Surg [Br] 2007;89:378-81.

7. Adegbehingbe OO, Oginni LM, Ogundele OJ, Ariyibi AL, Abiola PO, Ojo OD. Ponseti clubfoot management: Changing surgical trends in Nigeria. Iowa Orthop J 2010;30:7-14. 